\title{
A possible neuroendocrine basis of two clinical syndromes: Anorexia nervosa and the Kleine-Levin syndrome
}

\author{
J.K. YOUNG \\ Department of Anatomy, Center for the Health Sciences, UCLA, Los Angeles, California 90024
}

\begin{abstract}
Two clinical syndromes, anorexia nervosa and the Kleine-Levin syndrome, are reviewed and a neuroendocrine basis for each is proposed. The disturbances in food intake, appetite, activity, sleep, hormonal levels, and thermoregulation seen in anorexia nervosa are shown to be similar to the physiological effects of estrogen, whereas the opposite disturbances of the same functions that are present in Kleine-Levin patients are found to be producible with androgens. Hypothalamic hypersensitivity to sex steroids, arising from incomplete hypothalamic maturation during puberty, is postulated as a primary cause of the symptoms of both disorders.
\end{abstract}

Two clinical syndromes in which there are profound disturbances in the regulation of food intake and activity-anorexia nervosa and the Kleine-Levin 1 syndrome-are of interest because of the drastic behavioral changes involved and because each affliction seems remarkably sex-specific, overwhelmingly affecting female and male individuals, respectively. The possible hormonal basis of these syndromes will be examined here.

\section{ANOREXIA NERVOSA}

Anorexia nervosa, a syndrome occurring primarily in adolescent girls, has as its major symptom a drastic decline in body weight owing to persistent inanition by the sufferer. Loss of body weight is very severe, producing a condition of extreme emaciation and, infrequently, death by starvation-Hudgens (1974) estimates a death rate, even after attempts at treatment, of about $15 \%$. The disorder has been known and characterized for over 100 years; numerous reviews have been written on it, from which the symptoms discussed below have been derived (Bliss \& Branch, 1960; Bruch, 1970; Dally, 1969; King, 1963; Oberdisse, Solbach, \& Zimmermann, 1965; Rahman, Richardson, \& Ripley, 1939; Rowland, 1970; Russell \& Beardwood, 1968; Sours, 1969; Thomä, 1967).

The most striking symptom, aside from the appearance of chronic starvation, is a predominance among young girls below the age of 25 , with an onset typically at or around the time of puberty. More than $90 \%$ of true anorexic patients are female (Bliss, 1960; Dally, 1969; Thomä, 1967). King (1963) reports never having seen a case of male anorexia nervosa, and Dally records only six males out of a total 140 patients in his

I would like to gratefully acknowledge the helpful suggestions and criticisms of Dwight Nance and R. T. Rubin. study. Some of the males reported, furthermore, present with additional unusual characteristics, such as abnormally short stature (Bruch, 1970). Anorexia nervosa has traditionally been considered to be psychogenic in nature, and so this sex difference has long been presumed to reflect women's different psychological makeup, social standing, and position in the family. It seems appropriate, however, to ask to what extent sex hormones, namely estrogens, could account for the symptoms of the disorder and its predominance in women. After a brief review of other symptoms, a case will be made for a hypersensitivity of brain structures to estrogen as the primary cause of anorexia nervosa.

Other aspects of anorexia nervosa include abnormal attitudes toward food and eating, as evidenced by bizarre behavior: hiding of food to avoid eating a full meal; spontaneous or self-induced vomiting; frequent bowel movements and use of laxatives. Commonly, though not invariably, appetite disappears and food is pronounced to "taste bad." A marked increase in activity, particularly surprising in the face of extreme emaciation, appears and has been described as "remarkable, restless activity" (Bliss, 1960) and as “relentless hyperactivity" (Bruch, 1970). Insomnia often accompanies such an increase in activity. Illusions that a patient's body is bloated, distended, or grossly fat persist even after significant weight loss due to chronic dieting. The state of constant self-starvation is broken in many anorexics by episodes of bulimia, or compulsive ingestion of enormous amounts of food, that in one individual occurred "in vague, dreamy, detached state, almost as though she were sleepwalking. Subsequently she could recall nothing of the event" (Dally, 1969, p. 24).

Hormonal disturbances are also present. Amenorrhea is very common; it is clearly not the result of starvation, since it often appears before the onset of inanition (King, 1963; Rahman, et al., 1939; Thomä, 1967). This 
amenorrhea results from the abnormally low levels of luteinizing hormone found in anorexics (Beumont et al., 1973, 1974) that are apparently due to hypothalamic, and not pituitary, dysfunction, since LH-RH can stimulate a normal pituitary release of $\mathrm{LH}$ in anorexics (Wiegelmann \& Solbach, 1972). Several authors (Landon, Greenwood, Stamp, \& Wynn, 1966; Marks, Howorth, \& Greenwood, 1965; Neri, Ambrosi, Beck-Peccoz, Travaglini, \& Faglia, 1972) have reported abnormally high plasma levels of growth hormone in these patients, although this observation is not substantiated by Danowski, Livstone, Gonzales, Jung, \& Khurana (1972). Also, cortisol levels have been seen to be elevated (Angeli, Bocuzzi, Frairia, \& Bisbocci, 1972; Danowski et al., 1972; Green, van Dyck, \& Boschman, 1968; Landon et al., 1966; Marks et al., 1965). The contribution of starvation itself to these elevated hormone levels is undetermined; however, in anorexia, unlike in starvation, hormonal levels respond abnormally to various provocative or suppressive stimuli, such as hypoglycemia or dexamethasone, as reported by Angeli, Danowski, Marks, Neri, and their co-workers. Angeli et al., in particular, stress that the impairment of cortisol rhythm that they observed could not be considered a process of adpatation to undernutrition. Finally, a striking defect in the thermoregulatory response to cold has been found by Mecklenburg, Loriaux, Thompson, Andersen, \& Lipsett (1974) and by Wakeling and Russell (1970): anorexics do not respond to cold stress with shivering or vasoconstriction and can be separated from normal subjects on this basis. The authors considered this evidence for some hypothalamic defect. Landon et al. (1966) also observed intolerance to cold in their patients.

This bewildering array of symptoms has been traditionally regarded as arising from psychological tensions within the patients. This explanation is not altogether unreasonable. The strong influence of the mind upon the body, as in psychogenic amenorrhea (Reifenstein, 1946), is well known. However, an alternative explanation is available, since all of the physiological symptoms, at least, have one remarkable thing in common: they all can be produced, in varying degrees, by estrogen.

\section{Inanition, Poor Appetite}

The effects upon feeding in the rat of estrogen, whether administered systemically (Redick, Nussbaum, \& Mook, 1973; Sullivan \& Smith, 1957; Zucker, 1972), or implanted intracranially (Beatty, O'Briant, \& Vilberg, 1974; Wade \& Zucker, 1970a) are clear: feeding is substantially depressed. Similarly, a decreased motivation to feed is associated with estrus in the rat (Brobeck, Wheatland, \& Strominger, 1974; Jennings, 1973), and castration of females causes an increase in food intake (Holt, Keeton, \& Vennesland, 1936), showing that endogenous estrogen levels have the same effect. Comparable symptoms are produced by estrogen in the human. Estrogen administration, whether for therapeutic (Goodman \& Gilman, 1965; McCullagh, Beck, \& Schaffenburg, 1952) or for contraceptive purposes (Eckstein, Waterhouse, Bond, Mills, Sandilands, \& Shotton, 1961; Goldzieher, 1968; Nilsson, Jacobson, \& Ingemanson, 1967; Ziegler, Rodgers, Kriegsman, \& Martin, 1968) has a major side effect nausea or frank anorexia, particularly during the first 3 weeks of therapy. Such side effects of contraceptives, which have been definitely ascribed to the estrogen component (Segals \& Tietze, 1969) occur even when dosage ( McCullagh-.04 mg ethinylestradiol/day; Nilsson- $.05 \mathrm{mg}$ ethinylestradiol/day) is within the low physiological range $(.02-.05 \mathrm{mg} / \mathrm{day}-$ Merck index, 1960), a range which is generally employed by most mixed contraceptives. Nausea may also be present during early pregnancy, or at a point in the menstrual cycle where estrogen predominates, as discussed below. The relationship of estrogen to inanition in anorexia was most strikingly revealed in the work of Moulton (1942), who found that recurrent episodes of vomiting in one of her patients were correlated with peaks of estrogenic activity, as diagnosed by the appearance of cornified cells in vaginal smears. Even more in terestingly, Moulton attempted to ameliorate this periodic nausea with injections of testosterone and was met with surprising success. Following the injections, a "spectacular" improvement occurred, with remission of not only symptoms of nausea but also of neurotic and behavioral symptoms, allowing the patient to go home after a weight gain of $24 \mathrm{lb}$. Upon a subsequent relapse and readmission, estrogen injections were found to markedly worsen all symptoms, whereas further administration of testosterone produced temporary relief. It seems most peculiar, in view of the difficulty in treating anorexia nervosa, that this approach was not taken up by later investigators.

\section{Hyperactivity, Insomnia}

It has long been known that estrus in the rat is associated with increased locomotor activity (Wang, 1923). Colvin and Sawyer (1969) have shown this to be due to estrogen, which, in their animals, was most effective when implanted near the median forebrain bundle. Wade and Zucker (1970a), on the other hand, found the preoptic area to be the most effective site for estrogen stimulation of spontaneous locomotor activity. Similarly, Billings (1934) monitored spontaneous walking activity in the human over the course of the menstrual cycle by use of commerically available "pedometers." He found cyclic bursts of locomotor activity immediately after the days of menstrual flow and ascribed them to higher levels of "estrogenic hormones" present at those times. As regards sleep, Branchey, Branchey, \& Nadler (1971) have found that both the endogenous estrogen of proestrus and estrogen 
administration cause a marked decline in REM and NREM sleep in female rats. Analogous action in the human could partially explain the insomnia of anorexia nervosa.

\section{Amenorrhea, Low LH Levels}

Estrogen, when injected into rats (Rotchild \& Schwartz, 1965), implanted into the hypothalami of rhesus monkeys (Ferin, Carmel, Zimmerman, Warren, Perez, \& VandeWiele, 1974), or infused in small, physiological doses into women (VandeWiele, Bogumil, Dyrenfurth, Ferin, Jewelewicz, Warren, Rizkallah, \& Mikhail, 1970) has the capacity to suppress LH secretion. Estrogen presumably exerts a negative feedback suppression upon LH during some phases of the menstrual cycle, although it apparently facilitates LH secretion at critical points in the cycle.

\section{Elevated Cortisol, Growth Hormone Levels}

Palka, Zimmermann, \& Critchlow (1968) have shown that estrogen impairs the suppressive negative feedback effects of dexamethasone upon ACTH and adrenocorticoid secretion; this finding would seem to explain the elevated levels of corticoids normally seen in females as opposed to males of many species. Also, estrogen both stimulates a higher level of growth hormone secretion (Frantz \& Rabkin, 1965; Maw \& Wynn, 1972) and exerts a peripheral antagonism to growth hormone (Josimovich, Mintz, \& Finster, 1967; Schwartz, Wiedemann, Simon, \& Schiffer, 1969b) in women.

\section{Decreased Thermoregulatory Response to Cold}

Since the 1950s, sex steroids have been known to alter the thermoregulatory "set point" of many organisms. For example, progesterone is regarded as responsible for the peak in basal body temperature seen on the day of ovulation (Davis \& Fugo, 1948; Southam \& Gonzaga, 1965; Woolever, 1961). According to Wade (1972), however, progesterone is not the sole contributor to alterations in body temperature over the estrous cycle: "However, it is unlikely that thermogenic actions of progesterone alone can account for the fluctuations in body temperature during the estrous cycle. While progesterone injections raise rectal temperatures by only about $.3^{\circ} \mathrm{C}$, body temperature may drop $1^{\circ} \mathrm{C}$ from diestrus to proestrus in rats. Furthermore, it is difficult to understand how thermogenic effects of progesterone explain the drop in temperature at proestrus, because plasma progesterone levels are rising at this time. The elevated plasma estrogen titers at proestrus could be having hypothermic effects." This suggestion is based on the work of Nieburgs and Greenblatt (1948), who found that estrogen could lower the body temperature of ovariectomized rats. Also, it is consistent with the data of Buxton and Atkinson (1948), who followed the temper- ature responses of women to chronic estrogen treatment and concluded that "The temperature curves obtained from these patients during treatment indicate that estrogen may produce a slight depression of the basal temperature whereas progesterone, either with or without estrogen, produces a very definite rise." This action of estrogen may account for the poorer tolerance to cold seen in women as opposed to men (Hadland, Stock, \& Hewett, 1974). An exaggerated sensitivity to estrogen of a brain thermoregulatory center, which again could be embodied in the preoptic area (Wade, 1972), could explain the deficient thermoregulatory response to cold in anorexia nervosa.

Thus, it can be seen that all of the observed physiological symptoms of anorexia could be attributed to the known effects of estrogen. But anorexia has currently been treated as fundamentally a psychological disorder, and justifiably so, considering the prominent attitudinal and behavioral dysfunction present. Any explanation of the disorder must attempt to account for these psychological manifestations as well. Accordingly, psychological factors should be acknowledged as at least shaping and aggravating the syndrome; but it is evident from the data below that estrogen may markedly intensify such abnormal psychological attitudes.

The concept that hormones can influence emotions is not a new one. Altered personality or states of consciousness are well-known consequences of disorders such as Cushing's syndrome, Addison's disease, and hyperthyroidism (Engel \& Margolin, 1942; Michael \& Gibbons, 1963). Estrogen itself can alter personality in a phenomenon familar to millions of women: premenstrual tension. According to Suarez-Marias (1953), as much as $23 \%$ of all women frequently experience, with moderate severity, one or more of the common symptoms just prior to menstruation: marked restlessness, insomnia, nausea and vomiting, anxiety, sensations of bloating, tenderness of the breasts, irritability, moodiness, and others (Dalton, 1964; Morton, 1950). Occasionally, there is an exaggeration of premenstrual symptoms into frank psychotic episodes, with fears and hallucinations that "are not founded upon personality disturbances, as the patients were completely healthy in the first half of the cycle." (Bleuler, 1964). These symptoms were once a matter of great debate and were also held to be psychological in origin, until a physiological explanation was offered by Morton and others (Israel, 1953; Mall-Haefeli, 1974; Morton, 1950, 1953). The current consensus, based upon their investigations, is that symptoms of premenstrual tension are due to the sudden fall in progesterone levels just before menstruation and a consequent displacement of the estrogen-gestagen balance in favor of the estrogens. It should not be surprising, therefore, that severe symptoms of premenstrual tension can be successfully treated by administration of testosterone proprionate (Freed, 
1945 ) or a progestogen (Kane, Daly, Wallach, \& Keeler, 1966), both of which are known to antagonize the effects of estrogen.

The work of Benedek and Rubenstein (1939), who closely followed psychological changes in patients over the course of the menstrual cycle, affords a closer look at the psychological symptoms of the premenstrual tension, which they again attribute to the effects of estrogen unopposed by progesterone. The progestational, or luteal, phase of the cycle is characterized by moodiness, lethargy, and depression. As progesterone levels fall, these symptoms give way to new ones: feelings of inferiority, eliminative tendencies, fear of what will happen to one's body, fear of pain and mutilation, fears of birth and pregnancy. In dreams, fantasies of oral impregnation appear, along with confusion of relief of abdominal distension through birth with voiding and bowel movements. Dreams of a distorted body image occur: "My body is enormous. This is always connected with distension of my abdomen." "The striking similarity of these sensations to those expressed by anorexics is self-evident. They may be partly contingent upon the upcoming event of menstruation itself and so perhaps are not strictly analogous with those of anorexia nervosa. Nevertheless, their hormonal basis and their alleviation by means of hormones would seem to be quite significant.

A specific biochemical basis for some of the psychoactive properties of estrogen has emerged from more recent research. Estrogen has been shown to decrease the activity of monoamine oxidase in plasma and presumably in brain tissue as well, while progesterone increases monoamine oxidase activity (Briggs \& Briggs, 1972). Similar changes in MAO activity occur over the course of the menstrual cycle (Klaiber, Kobayashi, Broverman, \& Hall, 1971a; Klaiber, Broverman, Vogel, Abraham, \& Stenn, 1971b) in women. Grant and Pryse-Davies (1968) have found that the increased MAO activity produced by progesterone was associated with depression, whereas the drop in MAO activity produced by estrogen relieved symptoms of depression. This finding confirms earlier successful treatment of depression with estrogen (Sevringhaus, 1935) and agrees with Benedek and Rubenstein's (1939) characterization of the luteal phase of the menstrual cycle as associated with depression. It is also consistent with the fact that the most commonly used antidepressant drugs may act by altering brain amine levels and MAO activity (Bowman, Rand, \& West, 1968; Kopin, 1964). Thus, the potent psychoactive properties of estrogen seem firmly established and remarkably consistent with the symptoms seen in anorexia nervosa, which furthermore have been relieved in one case by administration of testosterone. These observations lessen the probability that the behavioral disturbances of anorexia nervosa are exclusively psychological in nature and make viable the assumption of estrogenic participation in their development.
How, then, would a postulated hypersensitivity of brain structures to estrogen come about? Conceivably, it would come about as a result of defective maturation of the hypothalamus as it undergoes the changes associated with puberty. There is considerable evidence that hypothalamic sensitivity to estrogen, as measured by estrogenic effectiveness in suppressing LH secretion, is dramatically higher before than after puberty, both in the rat (Eldridge, McPherson, \&\& Mahesh, 1974; McPherson, Eldridge, Costoff, \& Mahesh, 1974; Wade \& Zucker, 1970b) and in the human (Kelch, Grumbach, \& Kaplan, 1972; Kulin, Grumbach, \& Kaplan, 1972; Reiter, Kulin, \& Hamwood, 1974; Root, 1973; Widholm, Kantero, Axelson, Johansson, \& Wide, 1974). Kulin, Grumbach, and Kaplan (1972) estimate that the decline in sensitivity of the human hypothalamus during puberty may be as much as 500 -fold, a much greater change than that seen in the rat; Widholm et al. suggest that the process may not be complete until as late as 5 years after the menarche. It has been postulated that this desensitization is necessary for the type of LH regulation seen in postpuberal women.

On the other hand, the effects of estrogen upon feeding and activity cannot be produced in the rat until after puberty (Porterfield \& Stern, 1974; Wade \& Zucker, 1970b; Zucker, 1972). According to these investigators, this is not due to any maturational process of hypothalamic neurons themselves, but is dependent upon growth hormone and can be reversed by hypophysectomy. Estrogenic effects are accordingly not expressed until the growth phase of puberty is over. Thus, it can be seen that the sensitivity of hypothalamic neurons to estrogen may be determined by two complicated, and as yet poorly understood, processes at puberty: (1) a gradual maturational decrease in sensitivity to estrogen and (2) release of neurons concerned with feeding and activity from competing influences of growth hormone. Considering the magnitude of the sensitivity changes involved, even minor defects in either of these processes could result in a hypersensitivity to estrogen and the attendant symptoms of anorexia nervosa.

Is there, then, any evidence for such a hypersensitivity to estrogen in anorexia nervosa? Two studies (Beumont et al., 1973; Boyar, Katz, Finkelstein, Kapen, Weiner, Weitzman, \& Hellman, 1974a) indicate that there is indeed such a hypersensitivity, since patients respond to the anti-estrogen agent, clomiphene, with $\mathrm{LH}$ suppression rather than a normal rise. According to Root (1973), such a response to clomiphene indicates a sensitivity to the weak estrogenic properties of clomiphene, which acts by occupying receptor sites for estrogen (Korenman, 1970; Vaitukaitis, 1971). Children respond to clomiphene in the same way as anorexics; a "mature" response is obtained only after puberty and hypothalamic desensitization to estrogen. The basis of this "immature" response of anorexics to clomiphene is still subject to some debate, as it disappears upon 
substantial weight gain. The causality of this phenomenon is unclear; it is uncertain whether weight gain leads to decreased hypothalamic sensitivity or if a decreased sensitivity allows weight gain and recovery. These findings are therefore interesting, but not conclusive.

Possible reasons for an abnormal puberty in anorexia are, of necessity, difficult to adduce, owing to the present sparsity of knowledge about mechanisms of puberty. Anorexics are commonly overweight before onset of symptoms; Dally (1969) found that $62 \%$ of the patients he studied were previously overweight. Higher body weight is known to both increase sensitivity to estrogen (Redick et al., 1973; Zucker, 1972b) and to hasten the onset of puberty in man (Frisch \& Revelle, 1970). Since it is also known that anorexics often experience comparatively early puberty and breast development (Sours, 1969), the weight factor may contribute to the physiological as well as to the psychological features of the syndrome. The possibility that more profound developmental errors may be operating is supported by the finding that a statistically much higher than normal percentage of patients have a genetic abnormality, Turner's syndrome (Halmi \& DeBault, 1974; Kihlbom, 1969; Liston \& Shershow, 1974), or present with urogenital abnormalities (Halmi \& Rigas, 1973). The role of estrogen in these anorexic-Turner's syndrome patients may be indicated by the finding that these individuals have a partially defective, "mosaic" genotype (XO/XX). The ovaries of such individuals are commonly hypoplastic rather than absent and produce sufficient amounts of estrogen as to permit some degree of somatic feminization (Goldberg, Scully, Soloman, \& Steinbach; Morishima \& Grumbach, 1968). More significantly, there is some indication of hypothalamic hypersensitivity to estrogen in Turner's syndrome, since clomiphene fails to provoke a normal LH rise in Turner's patients, and indeed causes a slight LH reduction (Papanicolaou, Laraine, \& Charles, 1969). Evidence of abnormal brain sensitivity to steroids is also present in patients with another sex chromosome abnormality, Klinefelter's syndrome (XXY). Klinefelter's patients show a marked insensitivity to the negative feedback effects of testosterone (Cappell, Paulsen, Derleth, Skoglund, \& Plymate, 1973) and respond to clomiphene with a sharp decline in LH secretion (Weinstein, Kaplan, \& Grumbach, 1970). It is therefore clear that a genetic error in development can lead to abnormal sensitivity to sex steroids. Such a process may be operating in a significant fraction of anorexics and emphasizes the possibility that, as Kihlbom notes, "If the connection between Turner's syndrome and anorexia nervosa is more than incidental, it is conceivable that both organic and psychodynamic factors predispose patients with Tumer's syndrome for anorexia nervosa."
In summary, the postulation of a hypothalamic hypersensitivity to estrogen in anorexia nervosa is a concept that (1) has considerable explanatory power, (2) can be reasonably generated using existing models of puberty, and (3) is already supported by several studies of endocrine function in anorexia. It is in accord with the views of investigators such as Beumont, King, Mecklenburg, and Russell who have argued for a primary role of the hypothalamus in the disorder. Treatment of the syndrome using antiestrogen agents such as progesterone would seem indicated in light of this model and would, in any event, be useful, as progesterone is a relatively nontoxic agent known to increase food intake in rats (Hervey \& Hervey, 1967) and facilitate sleep in humans (Merryman, Boiman, Barnes, \& Rothschild, 1954).

\section{THE KLEINE-LEVIN SYNDROME}

The Kleine-Levin syndrome is of interest both as an entity in itself and as an example in males of dysfunction of the same neuroregulatory centers that are affected in anorexia nervosa. Since the disorder is almost entirely limited to males, much as anorexia nervosa is almost exclusively a female syndrome, it seems proper once again to inquire into the role of sex hormones in its genesis. It must be noted, however, that the Kleine-Levin syndrome is rarer, and therefore much less well studied, than anorexia nervosa. The effects of androgens upon nonsexual behavior have been, moreover, less extensively studied than those of female sex hormones. The brief discussion that follows should therefore be regarded more as a complement to the previous examination of anorexia nervosa than as a conclusive demonstration of the causative factors of the Kleine-Levin syndrome.

The main characteristics of the Kleine-Levin syndrome are attacks of sleep or drowsiness, lasting several days, in which the patient will sleep for as long as 12 to $20 \mathrm{~h}$ a day and wake up only for eliminative purposes or to eat enormous quantities of food (Barontini \& Zappoli, 1967; Critchley, 1962; Earle, 1965; Elian \& Bornstein, 1969; Finke \& Schulte, 1970; Garland, Sumner, \& Fourman, 1965; Kleine, 1925; Levin, 1936, Usdin, 1973) A sudden craving for sweets is often manifested, with ravenous ingestion of pies or syrup. Critchley, Garland, and Kleine observed sexual arousal, erotic fantasies, and exhibitionistic masturbation in their patients. Gallinek (1954) and Garland recorded fevers of $100^{\circ}$ and $103^{\circ} \mathrm{F}$ in their respective cases, and neurological dysfunction, such as an absent knee jerk reflex (Garland, 1965) or abnormal bursts of slow waves in the EEG (Barontini \& Zappoli, 1967; Elian \& Bornstein, 1969) was present in some patients. Only 3 female cases have been reported out of a total of 26 recorded in the literature, as reviewed by Gilbert (1964). Gilbert's female patient is of interest, 
since her symptoms recurred in monthly cycles; Periods of anxiety, low food intake, and hyperactivity alternated with periods of depression and lethargy, during which the attacks of sleep and overeating, with substantial weight gain, appeared. Gilbert unfortunately did not attempt to correlate these phases with the menstrual cycle. Kleine, however, did describe one female patient whose attacks of sleepiness always commenced several days prior to menstruation.

In all cases, onset occurred almost always between the ages of 14 and 20, i.e., at or around the time of puberty. After each episode, a patient typically is normal for several months and has no recollection of his behavior during an attack. It is possible to briefly summarize all these symptoms by simply saying they are the reverse of those appearing in anorexia nervosa: boys vs. girls, hyperphagia vs. anorexia, a craving for sweets vs. repugnance for food, somnolence vs. hyperactivity, hyperthermia vs. hypothermia. This observation of a "mirror image" relationship between the two syndromes is not new but was first suggested by Labbé (1954). His emphasis, however, was on a possible common psychological basis; here, neuroendocrine factors will be examined. To what extent can these symptoms be accounted for by the actions of sex hormones?

The effects of one sex steroid, progesterone, mimic many of the symptoms seen in the Kleine-Levin syndrome. In rats, progesterone administration leads to the appearance of sleep spindles in the cortical EEG (Terasawa \& Sawyer, 1970) and injection of as little as 100 micrograms of progesterone can produce a short period of sleep (Sawyer, 1969). Administration of large doses of progesterone in the human likewise produces periods of deep normal-appearing sleep (Merryman et al., 1954). Also, according to Jochims (1953), progesterone can be held responsible for the symptoms seen in a 12-year-old girl who was seized by an attack of sleepiness that lasted for 5 days, during which she slept almost continuously. Since all symptoms disappeared quickly and permanently within hours of the first menstrual flow, Jochims concluded that this exposure of brain structures to progesterone for the first time was somehow responsible. A similar explanation may account for the nine cases of sleep attacks in puberal girls reported by Wenzel (1960) that were also characterized by fever. Progesterone is capable of inducing fever (Davis \& Fugo, 1948; Southam \& Gonzaga, 1965), as was mentioned earlier. Consistent with these findings are the EEG changes produced by progesterone administration in the human (Ansari, Boyd, \& Centa, 1970; Velasco, Aznar, Gallegos, Velasquez, \& Cortes-Gallegos, 1974) and the slowing of cortical activity during pregnancy (Gibbs \& Reid, 1942).

In addition to affecting sleep and temperature, progesterone, whether administered systemically (Hervey, 1964) or implanted intracranially (Jankowiak \& Stern, 1974) will decrease running activity and increase feeding and body weight, by action upon hypothalamic nuclei. Thus, all of the symptoms present in the Kleine-Levin syndrome can be produced by the activation of hormone-sensitive brain structures by a sex steroid, progesterone. Progesterone could logically be the agent responsible for the symptoms seen in the three female patients.

However, progesterone is much less effective in stimulating feeding in male than in female rats (Hervey, 1964). This is presumably because males already have high levels of testosterone and because progesterone may well exert its effects indirectly by blocking the uptake and action upon the hypothalamus of estrogen (Rosner, Declerq de Perez Bedes, \& Gomez, 1974). Thus progesterone would be expected to be less potent in males and is an unlikely candidate for a hormonal mediator of Kleine-Levin symptoms. Nevertheless, progesterone has androgenic potency (Mountcastle, 1968), and it is not unreasonable to expect progesterone-sensitive neurons to respond to other androgens, as well. How do the effects of testosterone upon feeding and activity compare with those of progesterone?

Here, the evidence is less extensive. Testosterone restores to normal the lowered food intake and body weight of castrated male rats (Bell \& Zucker, 1971; Kakolewski, Cox, \& Valenstein, 1968) and thus alters feeding in the same way as progesterone. Testosterone also can induce a slowing of the $\alpha$ EEG rhythm in the human (Klaiber et al., 1971b) and a metabolite of testosterone, etiocholanone, induces fever (Kappas, Soybel, Glickman, \& Fukushima, 1960). The manifesting of sexual excitement during attacks certainly implies activation of testosterone-sensitive neurons, as testosterone seems to be the hormone of libido in men (Money, 1961). Jointly, the evidence concerning both progesterone and testosterone points to a hyperactivity of androgen-sensitive neurons as the underlying cause of the Kleine-Levin syndrome.

Such a hyperactivity, again, may result from incomplete maturation of the hypothalamus during puberty. Desensitization of the hypothalamus to androgens takes place in males, just as a similar process occurs in females with respect to estrogen (Bloch, Kragt, \& Masken, 1971; Eldridge \& Mahesh, 1975). Also, neurons involved both in the regulation of sleep and of $\mathrm{LH}$ and testosterone secretion seem to undergo joint alterations at puberty; during puberty, but not in pre- or postpuberal subjects, $\mathrm{LH}$ and testosterone levels show a hypnic rise during sleep (Boyar, Finkelstein, Roffwarg, Kapen, Weitzman, \& Hellman, 1972; Boyar, Rosenfeld, Kapen, Finkelstein, Roffwarg, Weitzman, \& Hellman, 1974b; Myers \& Drucker-Colin, 1974). These findings suggest an intimate relationship between sleep- and LH-regulatory neurons and highlight the imporatnce of puberty as an influence upon both sleep and LH secretion. A hypothalamic explanation of the disorder is, 
in any event, in accord with the general trend of thought about the Kleine-Levin syndrome, which is almost universally regarded as primarily an organic and not a psychogenic disorder. The opinion of Barontini and Zappoli (1967) is a representative one: "Considering ... the substantial psychic normality of the subjects between attacks (found also in our case) it seems to us that little importance is to be attributed, in the etio-pathology of this complex disturbance, to psychogenic factors." The sole exception to this general consensus is found in a case study by Haberland and Weissman (1968), who, while acknowledging the occurrence of such things as EEG abnormalities and poor tendon reflexes in some patients, nevertheless suggest the presence of a "maladaptive personality" as an underlying cause of the syndrome. One cannot but suspect that this explanation is offered not so much on the basis of firm supportive evidence but rather as a result of a lack of any other immediately apparent organic cause.

To conclude, the patterns of functional and behavioral disorder seen in anorexia nervosa and the Kleine-Levin syndrome suggest impairment of an identical array of functions in both syndromes, but in opposite "directions." This implies the existence of an integrated system of neurons jointly influencing food intake, activity, and body temperature that are themselves subject to influences of estrogen or testosterone. The conditions seen in these two clinical syndromes basically represent an exaggeration of the normal influences of sex hormones. Inasmuch as alterations in feeding, activity, and body temperature represent the major means of controlling energy input and ouput of an organism, these disorders can be regarded as defects in the hormonal regulation of energy balance.

\section{REFERENCES}

Angeli, A., Bocuzzi, G., Frairia, R., \& Bisbocci, D. Behavior of the circadian rhythm of adrenocortical secretion in anorexia nervosa in relation to the duration of amenorrhea. Folia Endocrinolocica, 1972, 25, 153-160.

Ansari, A. H., Boyd, J. R., \& Centa, C. J. Electroencephalographic recording during progestation treatment. Fertility and Sterility, 1970, 21, 873-882.

Barontini, F., \& Zappoli, R. A case of the Kleine-Levin syndrome. Clinical and polygraphic study. In H. Gastaut, E. Lugaresi, G. Berti Ceroni, and G. Coccagna (Eds.), The abnormalities of sleep in man. Bologna: Aulo Gaggi, 1967. Pp. 239-245.

Beatty, W. W., O'Briant, D. A., \& Vilberg, T. R. Suppression of feeding by intrahypothalamic implants of estradiol in male and female rats. Bulletin of the Psychonomic Society, 1974, 3, 273-274.

Bell, D. D., \& Zucker, I. Sex differences in body weight and eating: Organization and activation by gonadal hormones in the rat. Physiology \& Behavior, 1971, 7, 27-34.

Benedek, T., \& Rubenstein, B. B. The correlations between ovarian activity and psychodynamic processes: II. The menstrual phase. Psychosomatic Medicine, 1939, 1, 461-485.

Beumont, P. J. V., Carr, P. J., \& Gelder, M. G. Plasma levels of luteinizing hormone and of immunoreactive estrogen (estradiol) in anorexia nervosa: Response to clomiphene citrate. Psychological Medicine, 1973, 3, 495-501.

Beumont, P. J. V., Friesen, H. G., Gelder, M. G., \& Kolakowska, T. Plnsma prolactin and luteinizing hormone levels in anorexia nervosa. Psychological Medicine, 1974, 4, 219-221.
Billings, E. G. The occurrence of cyclic variations in motor activity in relation to the menstrual cycle in the human female. Bulletin of the Johns Hopkins Hospital, 1934, 54, 440-454.

Bleuler, M. Endokrinologishce Psychiatrie. In H. W. Gruhle (Ed.), Psychiatrie der Gegenwart, Band 1/1: Grundlagenforschung zur Psychiatrie, Teil B. Berlin: Springer Verlag, 1964. Pp. 161-252.

Bliss, E. L., \& Branch, C. H. H. Anorexia nervosa-its history, psychology, and biology. New York: Hoeber, 1960.

Bloch, G. J., Kragt, C. L., \& Masken, J. F. Plasma luteinizing hormone levels in male rats of various ages: Effects of castration and treatment with testosterone proprionate (TP). Federation Proceedings, 1971, 30, 475.

Bowman, W. C., Rand, M. J., \& West, G. B. Textbook of pharmacology. Oxford: Blackwell Scientific Publications, 1968. P. 605.

Boyar, R., Finkelstein, J., Roffwarg, H., Kapen, S., Weitzman, E., \& Hellman, L. Synchronization of augmented luteinizing hormone secretion with sleep during puberty. New England Journal of Medicine, 1972, 287, 582-586.

Boyar, R. M., Katz, J., Finkelstein, J. W., Kapen, S., Weiner, H., Weitzman, E. D., \& Hellman, L. Anorexia nervosa-immaturity of the 24-h luteinizing hormone secretory pattern. New England Joumal of Medicine, 1974, 291, 861-865. (a)

Boyar, R. N., Rosenfeld, R. S., Kapen, S., Finkelstein, J. W., Roffwarg, H. P., Weitzman, E. D., \& Hellman, L. Simultaneous augmented secretion of luteinizing hormone and testosterone during sleep. Joumal of Clinical Investigation, 1974, 54, 609-618. (b)

Branchey, L., Branchey, M., \& Nadler, R. D. The influence of sex hormones on brain activity in male and female rats. In $D$. H. Ford (Ed.), Influence of hormones on the nervous system. New York: Karger, 1971. Pp. 334-340.

Briggs, M., \& Briggs, $M$. The relationship between monoamine oxidase activity and sex hormone concentration in human blood plasma. Journal of Reproduction and Fertility, 1972, 29, 447-450.

Brobeck, J. R., Wheatland, M., \& Strominger, J. L. Variations in regulation of energy exchange associated with estrus, diestrus, and pseudopregnancy in rats. Endocrinology, 1947, 40, 65-72.

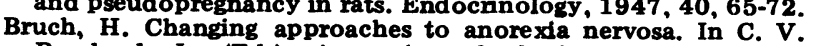
Rowland, Jr. (Ed.), Anorexia and obesity (Vol. 7, No. 1). Boston: Intemational Psychiatric Clinics, Little, Brown, 1970. Pp. 3-24.

Buxton, C. L., \& Atkinson, W. B. Hormonal factors involved in the regulation of basal body temperature during the menstrual cycle and pregnancy. Joumal of Clinical Endocrinology and Metabolism, 1948, 8, 544-549.

Capell, P. T., Paulsen, C. A., Derleth, D., Skoglund, R., \& Plymate, S. The effect of short-term testosterone administration on serum FSH, LH, and testosterone levels: Evidence for selective abnormality in LH control in patients with Klinefelter's syndrome. Joumal of Clinical Endocrinology, 1973, 37, 752-759.

Colvin, G. B., \& Sawyer, C. H. Induction of running activity by intra-cerebral implants of estrogen. Neuroendocrinology 1969, 4, 309-320.

Critchley, M. Periodic hypersomnia and megaphagia in adolescent males. Brain, 1962, 85, 627-656.

Dally, P. Anorexia nervosa. Bath, G. B: Pitman Press, 1969.

Dalton, $\mathrm{K}$. The premenstrual syndrome. London: Heinemann, 1964.

Danowski, T. S., Livstone, E., Gonzales, A. R., Jung, Y., \& Khurana, R. C. Fractional and partial hypopituitarism in anorexia nervosa. Hormones, 1972, 3, 105-118.

Davis, M. E., \& Fugo, N. W. The cause of physiologic basal temperature changes in women. Joumal of Clinical Endocrinology and Metabolism, 1948, 8, 550-563.

Earle, B. V. Periodic hypersomnia and megaphagia (the Kleine-Levin syndrome). Psychiatric Quarterly, 1965, 39, $79-83$.

Eckstein, P., Waterhouse, J. A. H., Bond, G. S., Mills, W. G. Sandilands, D. M., \& Shotton, D. M. The Birmingham oral contraceptive trial. British Medical Joumal, $1961,1172$.

Eldridge, J. C., McPherson III, J. C., \& Mahesh, V. B. Maturation of the negative feedback control of gonadotropin secretion in the female rat. End ocrinology, 1974, 94, 1536-1540.

Eldridge, J. C., \& Mahesh, V. B. Biology of Reproduction, in press, 1975.

Elian, M., \& Bornstein, B. The Kleine-Levin syndrome with intermittent abnormality in the EEG. Electroencephalography and Clinical Neurophysiology, 1969, 27, 601-604.

Engel, G. L., \& Margolin, S. G. Neuropsy chiatric disturbances in internal disease. Archives of Internal Medicine, 1942, 70, 236-259.

Ferin, M., Carmel, P. W., Zimmerman, E. A., Warren, M., Perez, R., \& VandeWiele, R. L. Location of intrahypothalamic estrogen-responsive sites influencing $\mathrm{LH}$ secretion in the female rhesus monkey. Endocrinology, 1974, 95, 1059-1068. 
Finke, J., \& Schulte, W. Schlafstörungen. Stuttgart: Verlag, 1970. P. 61.

Frantz, A. G., \& Rabkin, M. T. Effects of estrogen and sex difference on secretion of human growth hormone. Journal of Clinical Endocrinology and Metabolism, 1965, 25, 1470.

Freed, S. C. The treatment of premenstrual distress, with special consideration of the androgens. Journal of the American Medical Association, 1945, 127, 377-379.

Frisch, R. E., \& Revelle, R. Height and weight at menarche and a hypothesis of critical body weights and adolescent events. Science, $1970,169,397-399$.

Gallinek, A. Syndrome of episodes of hypersomnia, bulimia, and abnormal mental states. Journal of the American Medical Association, 1954, 154, 1081-1082.

Garland, H., Sumner, D., \& Fourman, P. The Kleine-Levin sy ndrome. Neurology, 1965, 15, 1161-1167.

Gibbs, F. A., \& Reid, D. E. The electroencephalogram in pregnancy. American Joumal of Obstetrics and Gynecology, $1942,44,672-675$

Gilbert, G. J. Periodic hypersomnia and bulimia. The Kleine-Levin syndrome. Neurology, 1964, 14, 844-850.

Goldberg, M. B., Scully, A. L., Soloman, I. L. \& Steinbach, H. L. Gonadal dysgenesis in phenotypic female subjects-a review of eighty-seven cases, with cytogenic studies in fifty-three. American Journal of Medicine, 1968, 45, 529-543.

Goldzieher, J. W. The incidence of side effects with oral or intrauterine contraceptives. American Joumal of Obstetrics and Gynecology, 1968, 102, 91-94.

Goodman, L. S., \& Gilman, A. The pharmacological basis of therapeutics (3rd ed.). London: MacMillan, 1965. P. 1548.

Grant, E. C. G., \& Pryse-Davies, J. Effect of oral contraceptives on depressive mood changes and on endometrial monoamine oxidase and phosphatases. British Medical Joumal, 1968, 3, 777-780.

Green, O. C., van Dyck, P., \& Boschman, M. M. Pituitary insufficiency in anorexia nervosa. Joumal of Pediatrics, 1968 , $72,572-573$

Haberland, C., \& Weissman, S. The Kleine-Levin syndrome: A case study with a psychopathologic approach. Acta Psychiatrica Scandinavica, 1968, 44, 1-10.

Hadland, D. G., Stock, J. F., \& Hewett, M. I. Heat and cold tolerance: Relation to body weight. Postgraduate Medicine, $1974,55,75-80$.

Halmi, K. A., \& Rigas, C. Urogenital malformations associated with anorexia nervosa. British Joumal of Psy chiatry, 1973, $122,79-81$.

Halmi, K. A., \& DeBault, L. E. Gonosomal aneuploidy in anorexia nervosa. American Journal of Human Genetics, $1974,26,195-198$

Hervey, G. R. Effects of progesterone of energy balance in rats. Nutrition Society Proceedings, 1964, 23, xxii.

Hervey, E., \& Hervey, G. R. The effects of progesterone on body weight and composition in the rat. Joumal of Endocrinology $1967,361-384$

Holt, H., Keeton, R. W., \& Vennesland, B. The effect of gonadectomy on body weight in albino rats. American Journal of Physiology, 1936, 114, 515-525.

Hudgens, R. W. Psychiatric disorders in adolescents. Baltimore: William \& Wilkins Co., 1974. P. 199.

Israel, S. L. The clinical pattern and etiology of pre-menstrual tension. International Record of Medicine, 1953, 166, 469-474.

Jankowiak, R., \& Stem, J. J. Food intake and body weight modification following medial hypothalamic hormone implants in female rats. Physiology and Behavior, 1974, 12 , 875-879.

Jennings, W. A. Estrus anorexia: Single-tube intake and bar-press rate in the albino rat. Physiological Psychology, 1973, 1 369-372.

Jochims, J. Schlafsucht als Auftakt zur Menarche. Archiv für Kinderheilkunde, 1953, 147, 156-158.

Josimovich, J. B., Mintz, D. H., \& Finster, J. L. Estrogenic inhibition of growth hormone-induced tibial epiphyseal growth in hypophysectomized rats. Endocrinology, 1967, 81 , 1428-1430.

Kakolewski, J. V., Cox, V. C., \& Valenstein, E. S. Sex differences in body weight changes following gonadectomy of rats. Psychological Reports, 1968, 22, 547-554.

Kane, F. J., Daly, R. J., Wallach, M. H., \& Keeler, M. H. Amelioration of premenstrual mood disturbance with a progestational agent (enovid). Diseases of the Nervous System, $1966,27,339-342$

Kappas, A., Soybel, W., Glickman, P., \& Fukushima, D. K. Fever producing steroids of endogenous origin in man. Archives of Internal Medicine, 1960, 105, 701-708.

Kelch, R. P., Grumbach, M. M., \& Kaplan, S. L. Studies on the mechanism of puberty in man. In B. B. Say ena, C. G. Beling. and H. M. Gandy (Eds.), Gonadotropins. New York: Wiley, 1972. Pp. 524-534.

Kihlbom, M. Psychopathology of Turner's syndrome, Acta Paedopsychiatrica, 1969, 36, 75-81.
King, A. Primary and secondary anorexia nervosa syndromes. British Journal of Psy chiatry, 1963, 109, 470-479.

Klaiber, E. L., Kobayashi, Y., Broverman, D. M., \& Hall, F. Plasma monoamine oxidase activity in regularly menstruating women and in amenorrheic women receiving cyclic treatment with estrogens and a progestin. Joumal of Clinical Endocrinology and Metabolism, 1971, 33, 630-638. (a)

Klaiber, E. L., Broverman, D. M., Vogel, W., Abraham, G. E., \& Stenn, P. G. Effects of testosterone on mental performance and EEG. In D. H. Ford (Ed.), Influence of hormones on the nervous system. New York: S. Karger, 1971. Pp. 341-353. (b)

Kleine, W. Periodische Schlafsucht. Monatsschrift für Psychiatrie und Neurologie, $1925,57,285-320$.

Kopin, I. J. Storage and metabolism of catecholamines: The role of monoamine oxidase. Pharmacological Reviews, 1964, 16, 179-191.

Korenman, S. G. Relation between estrogen inhibitory activity and binding to cytosol of rabbit and human uterus. Endocrin ology, 1970,1119-1123.

Kulin, H. E., Grumbach, M. M., \& Kaplan, S. L. Gonadal-hypothalamic interaction in prepubertal and pubertal man: Effect of clomiphene citrate on urinary follicle-stimulating hormone and luteinizing hormone and plasma testosterone. Pediatric Research, 1972, 6, 162-171.

Labbé, P. L.-A. L'anorexie mentale. Acta Neurologica et Psy chiatrica Belgica, 1954, 52, 164-174.

Landon, J., Greenwood, F. C., Stamp, T. C. B., \& Wynn, V. The plasma sugar, free fatty acid, cortisol and growth hormone response to insulin, and the comparison of this procedure with other tests of pituitary and adrenal function. II. In patients with hypothalamic or pituitary dysfunction or anorexia nervosa. Joumal of Clinical Investigation, 1966, 45, 437-449.

Levin, M. Periodic somnolence and morbid hunger: A new sy ndrome. Brain, 1936, 59, 494-504.

Liston, E. H., \& Shershow, L. W. Concurrence of anorexia nervosa and gonadal dysgenesis. Archives of General Psy chiatry, 1974, 29, 834-836.

Mall-Haefeli, M. Die hormonale Antikonzeptionen und Ihre Auswirkungen auf die Psyche. Schweizenische Medizinisch Wochenschrift, 1974, 104, 878-886.

Marks, V., Howorth, N., \& Greenwood, F. C. Plasma growth-hormone levels in chronic starvation in man. Nature, $1965,208,686-687$.

Maw, D. S. J., \& Wynn, V. The relation of growth hormone to altered carbohydrate metabolism in women taking oral contraceptives. Journal of Clinical Pathology, 1972, 25, 354-358

McCullagh, E. P., Beck, J. C., \& Schaffenburg, C. Disappearance of diabetes during estrogen therapy in acromegaly. Cleveland Clinical Quarterly, 1952, 19,121-126.

McPherson III, J. C., Eldridge, J. C., Costoff, A., \& Mahesh, V. B. The pituitary-gonadal axis before puberty: Effects of various estrogenic steroids in the ovariectomized rat. Steroids. $1974,24,41-56$.

Mecklenburg, R. S., Loriaux, D. L., Thompson, R. H., Andersen, A. E., \& Lipsett, M. B. Hypothalamic dysfunction in patients with anorexia nervosa. Medicine, 1974, 53, 147-159.

Merck index of chemicals and drugs (7th ed.). Rahway, N. J: Merck, 1960. P. 438.

Merryman, W., Boiman, R., Barnes, L., \& Rothschild, I Progesterone "anesthesia" in human subjects. Journal of Clinical Endocrinology \& Metabolism, 1954, 14, 1567-1569.

Michael, R. P., \& Gibbons, J. L. Interrelationships between the endocrine system and neuropsy chiatry. International Reviews of Neurobiology, 1963, 5, 243-302.

Money, J. Components of eroticism in man: $I$. The hormones in relation to sexual morphology and sexual desire. Joumal of Nervous and Mental Disease, 1961, 132, 239-248.

Morishima, A., \& Grumbach, M. M. The interrelationship of sex chromosome constitution and phenotype in the syndrome of gonadal dysgenesis and its variants. In A. R. Kaplan and M. A Kelsall (Eds.), Annals of the New York Academy of Sciences: Leukocyte chemistry and morphology correlated with chromosome anomalies (Vol. 155). New York: New York Academy of Sciences, 1968. Article 3, pp. 695-715.

Morton, J. H. Premenstrual tension. American Journal of Obstetrics and Gynecology, 1950, 60, 343-352.

Morton, J. H. Editorial. International Record of Medicine, 1953. $166,463$.

Moulton, R. A psychosomatic study of anorexia nervosa, including the use of vaginal smears. Psychosomatic Medicine, $1942,4,62-74$.

Mountcastle, V. Medical physiology (12th ed.). St. Louis: Mosby, 1968. P. 1012

Myers, R. D., \& Drucker-Colin, R. R. Neurohumoral coding of brain function. New York: Plenum Press, 1974, P. 362.

Neri, V., Ferrari, C., Beck-Peccoz, P., Ambrosi, B., Faglia, G., \& Travaglini, P. Plasma growth hormone in anorexia nervosa. In A. Pecile and E. E. Muller (Eds.), Second international symposium on growth hormone, abstracts. Amsterdam: Excerpta Medica Foundation, 1971. P. 69. 
Neri, V., Ambrosi, B., Beck-Peccoz, P., Travaglini, P., \& Faglia, G. Growth" hormone"regulation and hypothalamic-pituitary-adrenal function in anorexia nervosa. Folia Endocrinologica, 1972, 25, 143-152.

Nieburgs, H. E., \& Greenblatt, R. B. The role of the endocrine glands in body temperature regulation. Journal of Clinical Endocrinology, 1948, 8, 622-623.

Nilsson, A., Jacobson, L., \& Ingemanson, C.-A. Side effects of an oral contraceptive with particular attention to mental symptoms and sexual adaptation. Acta Obstetrica et Gy necologica Scandinavica, 1967, 46, 537-556.

Oberdisse, K., Solbach, G., \& Zimmermann, H. Die endokrinologischen Aspekte der Anorexia nervosa. In J.-E. Meyer and H. Feldman (Eds.), Anorexia nervosa-Symposium 1965, Gottingen. Stuttgart: Verlag, 1965. Pp. 21-35.

Palka, Y. S., Zimmermann, E., \& Critchlow, V. Influence of estrogen on feedback control of pituitary-adrenal function. In Proceedings of the 24th International Congress of Physiological Sciences, Abstracts of Volunteer Papers and Films (Vol. 7). Washington, D. C: International Union of Physiological Sciences, 1968. P. 335.

Papanicolaou, A. D., Loraine, J. A., \& Charles, D. Pituitary-gonadotropic function in Turner's syndrome Lancet, 1969, 1, 184-186.

Porterfield, A. L., \& Stern, J. J. Growth hormone and the refractoriness of the prepuberal activity system to estradiol in the rat. Phy siological Psychology, 1974, 2, 23-25.

Rahman, L., Richardson, H. B., \& Ripley, H. S. Anorexia nervosa, with psychiatric observations. Psychosomatic Medicine, 1939, 1, 335-365.

Redick, J. H. Nussbaum, A., \& Mook, D. G. Estradiol induced suppression of feeding in the female rat: Dependence on body weight. Physiology and Behavior, 1973, 10, 543-547.

Reifenstein, E. C. Psychogenic or "hy pothalamic" amenorrhea. Medical Clinics of North America, 1946, 30, 1103-1114.

Reiter, E. O. Kulin, H. E., \& Hamwood, S. M. The absence of positive feedback between estrogen and luteinizing hormone in sexually immature girls. Pediatric Research, 1974, 8, 740-745.

Root, A. W. Endocrinology of puberty. Journal of Pediatrics, 1973, 83, 1-19.

Rosner, J. M., Declerq de Perez Bedes, G., \& Gomez, E. Competition between estradiol and various progestins in the rat hypothalamus. Annales d'Endocrinologie, 1974, 35, 173-176.

Rotchild, I., \& Schwartz, N. B. The corpus luteum-hypophysis relationship. Acta Endocrinologica, 1965, 49, 120-137.

Rowland, Jr., C. V. Anorexia nervosa-a survey of the literature and review of thirty cases. In C. V. Rowland, Jr. (Ed.) Anorexia and obesity (Vol. 7, No. 1). Boston: Intemational Psy chiatry Clinics, Little, Brown, 1970. Pp. 37-137.

Russell, G. E. M., \& Beardwood, C. J. The feeding disorders, with particular reference to anorexia nervosa and its with particular reference to anorexia nervosa and its Endocrinology and human behaviour: Conference, May 1967. Oxford: Oxford University Press, 1968. Pp. 310-329.

Sawyer, C. H. Some effects of hormones on sleep. Experimental Medicine and Surgery, 1969, 27, 177-186.

Schwarte, E., Echemendia, E., Schiffer, M., \& Panariello, V. A. Mechanism of estrogenic action in acromegaly. Journal of Clinical Investigation, 1969, 48, 260-269. (a)

Schwartz, E., Wiedemann, E., Simon, S., \& Schiffex, M. Estrogen anatognism of metabolic effects of administered growth hormone. Joumal of Clinical Endocrinology and Metabolism, 1969, 29, 1176-1181. (b)

Segal, S. J., \& Tietze, C. Contraceptive technology: Current and prsopective methods. In Reports on population/family planning. New York: Population Council and the International Institute for the Study of Human Reproduction, Columbia University, 1969. P. 1.

Sevringhaus, E. L. The relief of menopause symptoms by estrogenic preparations. Journal of the American Medical Association, 1935, 104, 624-628.

Sours, J. A. Anorexia nervosa: Nosology, diagnosis, developmental patterns, and power-control dynamics. In $G$ Caplan and S. Lebovici (Eds.), Adoleacence: Psychococial perspectives. London/New York: Basic Books, 1969.

Southam, A. L., \& Gonzaga, F. $\bar{P}$. Systemic changes during the menstrual cycle. American Journal of Obstetrics and Gynecology, 1965, 91, 142-165.

Suarez-Marias, $E$. The psychophysiologic syndrome of prementrual tension, with emphasis on the psychiatric aspect. International Record of Medicine, 1953, 166, 475-486.
Sullivan, L. W., \& Smith, T. C. Influence of estrogens on body growth and food intake. Society for Experimental Biology and Medicine, Proceedings, 1957, 96, 60-64.

Terasawa, E., \& Sawyer, C. H. Diurnal variation in the effects of progesterone on multiple unit activity in the rat hypothalamus. Experimental Neurology, 1970, 27, 359-374.

Thomä, H. Anorexia nervosa. New York: International Universities Press, Inc., 1967.

Usdin, G. Sleep research and clinical practice. New York: Brunner/Mazel, 1973.

VandeWiele, R. L., Bogumil, J., Dyrenfurth, I., Ferin, M., Jewelewicz, R., Warren, M., Rizkallah, T., \& Mikhail, G. Mechanisms regulating the menstrual cycle in women. Recent Progress in Hormone Research, 1970, 26, 63-103.

Vaitukaitis, J. L., Vermudez, J. A., Cargille, C. M., Lipsett, M. B., \& Ross, G. T. New evidence for an anti-estrogenic action of clomiphene citrate in women. Journal of Clinical Endocrinology, 1971, 32, 503-508.

Velasco, M. Aznar, R. Gallegos, A. J., Velasquez, $\mathbf{X}$ Cortes-Gallegos, V. EEG abnormalities found in healthy women under contraceptive medication II. Long-term studies. Clinical Electroencephalography, 1974, 5, 61-66.

Wade, G. N., \& Zucker, I. Modulation of food intake and locomotor activity in female rats by diencephalic hormone implants. Journal of Comparative Physiology and Psychology, 1970, 72, 328-336. (a)

Wade, G. N., \& Zucker, I. Development of hormonal contro over food intake and body weight in female rats. Journal of Comparative Physiology and Psychology, 1970, 70, 213-220. (b)

Wade, G. N. Gonadal hormones and behavioral regulation of body weight. Physiology and Behavior, 1972, 8, 523-534.

Wakeling, A., \& Russell, G. F. M. Disturbances in the regulation of body temperature in anorexia nervosa. Psychological Medicine, 1970, 1, 30-39.

Wang, G. H. The relation between "spontaneous" activity and the oestrous cycle in the white rat. Comparative Psychology Monographs, 1923, 2, 1-27.

Weinstein, R. L., Kaplan, S. L., \& Grumbach, M. M. Gonadal and pituitary insensitivity to HCG and clomiphene stimulation in Klinefelter's syndrome. 53rd Meeting of the Endocrine Society, Abstracts, 1970, p. A102.

Wenzel U. Periodische Umdämmerungen in der Pubertät. Archiv für Psychiatrie and fur die gesamte Neurologie, 1960, 201, 133-150.

Widholm, O., Kantero, R.-L., Axelson, E., Johansson, E. D. B., \& Wide, $L$. Endocrine changes before and after the menarche 1 . Urinary excretion of estrogen, FSH, and LH, and serum levels of progesterone, FSH, and LH. Acta Obstetrica et Gynecologica Scandinavica, 1974, 53, 197-208.

Wiegelmann, W., \& Solbach, H. G. Effects of LH-RH on plasma levels of LH and FSH in anorexia nervosa. Hormone and Metabolic Research, 1972, 4, 404.

Woolever, C. A. Daily plasma progesterone levels during the menstrual cycle. American Journal of Obstetrics and Gynecology, 1961, 85, 981-988.

Ziegler, F. J., Rodgers, D. A., Kriegsman, S. A., \& Martin, P. L. Ovulation suppressors, psy chological functioning, and marital adjustment. Joumal of the American Medical Association. 1968, 204, 849-853.

Zucker, I. Body weight and age as factors determining estrogen responsiveness in the rat feeding system. Behavioral Biology, $1972,7,527-542$.

\section{NOTE}

1. Recently M. Billiard, C. Guilleminault, and W. C. Dement have reported (Neurology, 1975, 25, 435-443) observing KleineLevin-type symptoms in a 13-year-old girl that recurred consistently during the progestational phase of her menstrual cycle. They implicated progesterone in the genesis of these symptoms and were able to successfully treat them with administration of conjugated estrogens.

(Received for publication February 28, 1975 revision accepted April 16, 1975.) 